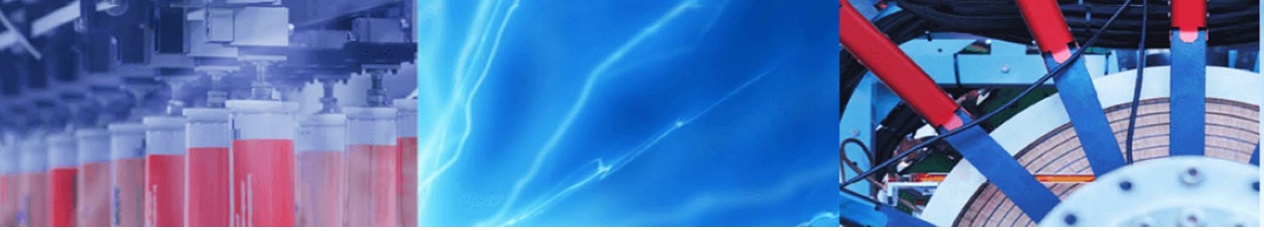

Research Article

\title{
The effect of geocell dimensions and layout on the strength properties of reinforced soil
}

\author{
Mohsen Kabiri Kouchaksaraei ${ }^{1}$ [D Ahad Bagherzadeh Khalkhali $^{1}$
}

Received: 12 June 2020 / Accepted: 1 September 2020 / Published online: 15 September 2020

(c) Springer Nature Switzerland AG 2020

\begin{abstract}
Selecting suitable materials with acceptable shear strength characteristics may be the easiest and most economical way to obtain the maximum shear strength, if possible. But, it is costly in some projects, due to the long distances to access the source of high-quality materials, as well as environmental constraints. Therefore, this study intends to adopt a more appropriate strategy in order to achieve desired strength properties using 3D geosynthetic reinforcement called geocell. In this study, both laboratory experiments and numerical analyses were employed to investigate the layout-dependent and dimensional effects of geocell on the shear strength of reinforced soil in various sections of a reinforcing element. Experimental outputs were extended using numerical simulation through the finite element method. The results indicated that geocell with smaller pocket opening diameter increased the shear strength of soil up to $31 \%$. It was also observed that despite the increase in the pocket opening diameter (up to $80 \%$ ), only $4 \%$ decrement occurred in the value of shear strength. Due to the increase in the aspect (height-diameter) ratio of geocell, the interface shear strength between the soil and geocell edge increased. When the failure plane exactly passed through the middle of the geocellheight, the shear strength is increased by $11 \%$, in comparison with the state that the edge of geocell is tangential to the failure plane. However, when the geocell moved away from the failure plane, the shear stress-horizontal displacement curves had a similar trend to that of the unreinforced soil.
\end{abstract}

Keywords Finite-element modeling · Laboratory tests · Reinforced soil

\section{Introduction}

One of the main disturbing problems which geotechnical engineers are continually encountering is finding a solution to improve the strength properties of earth structures depending on the type of project and its financial budget. The selection of suitable materials with acceptable shear strength characteristics is the easiest and often the most economical method. However, there is not cost-effective access to high-quality material resources at all times. Therefore, other strategies should be adopted in order to achieve the desired strength characteristics.
In the history of building materials technology, soil is a material that has relatively good compressive and shear strengths and almost no tensile strength. However, to improve its engineering properties, especially the tensile strength, soil can be reinforced [1, 2]. In ancient times, soil reinforcement consisted of mixing straw with mud, reinforcing with woven reeds, and using branches and other plant material to improve strength and capacity to support greater loads [1]. Modern soil reinforcement uses stronger and more durable materials, but employs many of the same fundamental mechanisms that provided strength in these early applications. Early versions of modern soil reinforcement were developed in the early 1960s with Henri

Mohsen Kabiri Kouchaksaraei, Mohsen.kabiri@srbiau.ac.ir| ${ }^{1}$ Department of Civil Engineering, Science and Research Branch, Islamic Azad University, Tehran, Iran. 
Vidal's patented Reinforced Earth for construction of selfsupporting retaining walls. These walls were constructed using galvanized steel strips with ribs to provide lateral resistance against earth pressures [3].

Since the mid-twentieth century, simultaneously with the advent of polymers, a much more stable substance called geosynthetics became demanded. Geosynthetics can provide enhanced confinement to the soil by increasing its strength and stiffness [4]. Nowadays, these have gained popularity as reinforcement materials in the construction of geosynthetic-reinforced soil (GRS) structures (e.g., retaining walls, slopes, embankments, abutments, etc.), and they are using, very widely [5]. Improving the resistance of weak soil using geosynthetic material is a successful way to support the stability of many geotechnical engineering structures such as dams, road construction, excavations, slopes and foundations [6]. Soil reinforcement not only increases soil resistance parameters but also can consequent some economic benefits, due to a cost-saving stemming from controlled use of local fill materials and improved overall stability and increased safety coefficients. As a result of the safety factor increment, the usage of geocell reinforcement for sub-ballast may increase the allowable train speed by almost 5-25\% [7]. The mechanism of the reinforcement action is mainly influenced by the two factors of interface friction between the soil and reinforcement and a passive pressure due to the interlocking between the soil particles and reinforcement when it has appendages or pocket [8]. The geocell is a three-dimensional product of geosynthetics, which is made of polymer materials with the polymer bands connected at certain intervals [9]. The term geocell refers to cellular (often honeycomb shape when expanded) geosynthetic products [10].

In comparison with the non-geocell state, higher bearing capacity and lower settlement are other advantages of geocell, which are used to improve poor earth materials [11]. However, it must be noted that according to the BS 8006 [12], in the construction of reinforced embankments over soft and very soft foundation soils, the main aim is to control the stability rather than to reduce settlements.

Some researchers presented parametric results that could be used to obtain the strength and stiffness of the confined region with the geocell $[13,14]$. Practically, utilizing this parametric method, the geocell-reinforced soil can be simplified, to a layer of homogeneous and isotropic composite material with the estimated equivalent strength and stiffness parameters [10]. Based on analyses, geocell may model as a beam element, which has the frictional properties of the base soil and at the same time, its cohesion and modulus of elasticity increases, and this element can carry both bending and membrane stresses [15]. The vertical stress distribution patterns observed in the subsoil show that the normal pressures were redistributed well within the geocell mattress and transmitted insignificant pressure to the subsoil in comparison with those in unreinforced soils [16]. Using a laboratory model, it was found that a geocell with greater height would lead to a relatively uniform distribution of pressure, compared to the one with a lower height [17]. Besides, the higher ratio of height to diameter of the geocell called aspect ratio can improve the benefit of geocell. Thus, keeping constant the height of geocell, and decreasing the diameter of its pockets, result in interfacial shear strength between the soil and reinforcement increases [18].

Based on a statement resulted from direct shear tests on dry mixtures of sand and clay, the shear strength of the mixture is affected by the concentration by weight of the sand in the mixtures. For instance, when the concentration of sand varies between 40 and $75 \%$, the shear strength of the mixture is provided in part by the shear strength of the clay and in part by the frictional resistance between the sand grains. Less and more amounts of sand make the domination role for clay cohesion or friction between the sand particles in determining the shear strength of the mixture, respectively [19]. Numerical simulations demonstrated that the best redistribution of the load is achieved if reinforcements are placed up to a certain depth depending on the loading width [20-22]. Through experiments and numerical simulations, it was showed that confinement through geocell effectively increases the stiffness and strength of the ballast and decreases vertical settlement and lateral dispersion $[11,23]$. In a study conducted on geocell-reinforced soils using extra-large scale direct-shear testing equipment with $500 \times 500 \times 400 \mathrm{~mm}$ dimension, a cohesion increment of $244 \%$, was indicted, in the sample with geocell reinforcing materials [24].

In the present study, using a numerical method, the effect of geocell dimensions was examined, aiming to test the sensitivity of the reinforced soil strength to dimensional changes of geocell reinforcement. Designing geocells with a larger aspect ratio, in addition to making more problems in the practical works (the installation process of geocell and soil compaction), also imposes more costs on soil improvement projects. Therefore, having enough information about the value of the effect of geocell dimensions could help the designer engineer make the proper decision. Additionally, it was attempted to investigate the variations of soil shear strength between the two reinforcements. Hence, the changes in the location of geocell placement, to assess the effectiveness of the reinforcing element emplacement, in the case of executive errors of the geocell installation location, was studied. 
Table 1 Soil engineering characteristics

\begin{tabular}{|c|c|c|c|c|c|c|c|}
\hline \multirow[t]{2}{*}{ Type of soil } & \multicolumn{2}{|c|}{ Classification } & \multirow{2}{*}{$\begin{array}{l}\text { Average particle size } \\
D_{50}(\mathrm{~mm})\end{array}$} & \multirow{2}{*}{$\begin{array}{l}\text { Maximum dry density } \\
\left(\mathrm{kN} / \mathrm{m}^{3}\right)\end{array}$} & \multirow{2}{*}{$\begin{array}{l}\text { Optimum moisture } \\
\text { content (\%) }\end{array}$} & \multirow[t]{2}{*}{ Cohesion (kPa) } & \multirow[t]{2}{*}{ Friction angle } \\
\hline & Unified & AASHTO & & & & & \\
\hline $\mathrm{F}$ & SM & $A-1-b$ & 0.9 & 20.9 & 7.2 & 7.4 & 34.9 \\
\hline
\end{tabular}

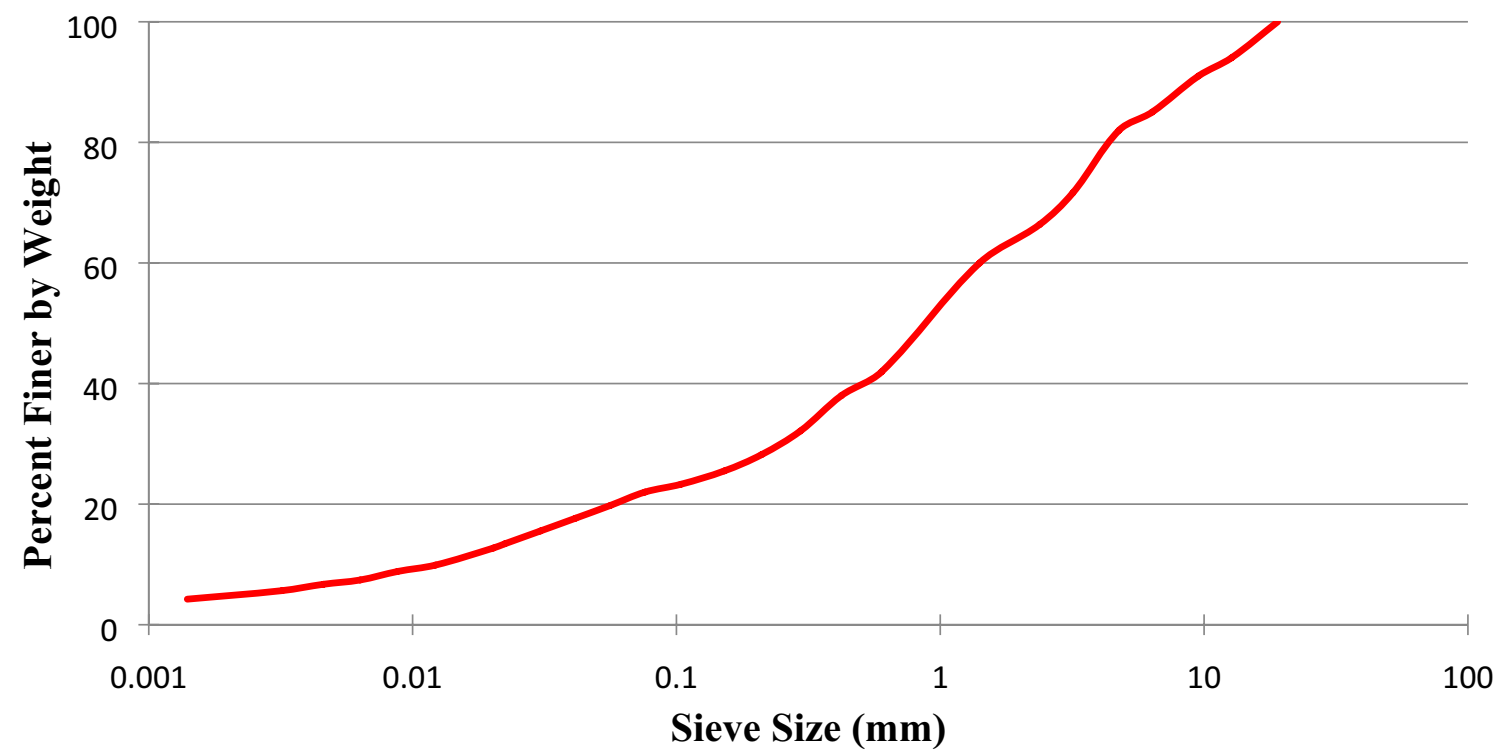

Fig. 1 Grain size distribution curve of soil

\section{Materials and methods}

\subsection{Specifications of materials and laboratory results used in modeling}

The laboratory tests were employed to determine the strength parameters of the soil and reinforcement used in the model. The soil was collected from a site located in the north of Semnan. The test specimen was produced by a change in the soil granulometry to achieve a middle curve of the subbase material for column " $F$ " of the AASHTO M 147 code [25]. Geocell manufacturing was done using available polymeric sheets.

\subsubsection{Soil properties}

The engineering properties of grained soil used in this study and the particle size distribution curve are presented in Table 1 and Fig. 1, respectively. The specific gravity of soil particles is achieved by 2.631 , following ASTM D854, ASTM C127 and ASTM C128 [26-28]. The soil compaction curve, as well as the zero void line, are shown in Fig. 2. As is observable, the peak of

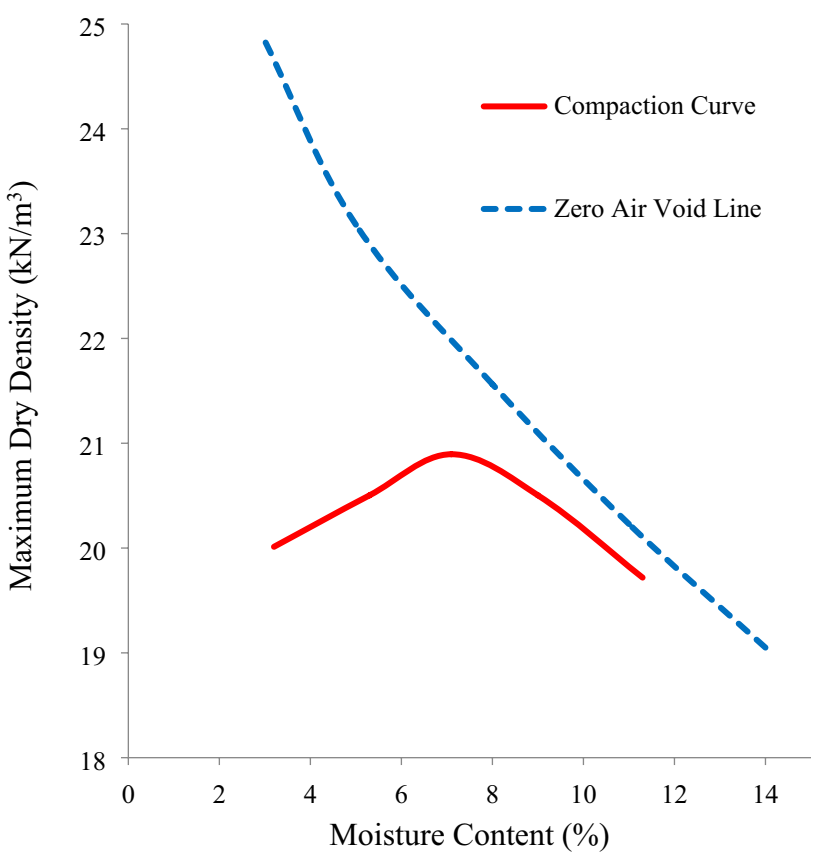

Fig. 2 The compaction curve, and zero air void line of the soil 
the compaction curve shows that using ASTM D1557 method [29], the soil is achieved to a relative density of $95 \%$, compared to the maximum theoretical value.

The soil was remoulded by $90 \%$ of relative compaction, to achieve the dry density of $18.8 \mathrm{kN} / \mathrm{m}^{3}$. This density achieved, placing a predetermined weight of soil, regarding the degree of compaction in optimal moisture conditions, in a given volume of shear box. The direct shear tests were conducted in accordance with BS 1377 [30] at the optimum moisture content.

\subsubsection{Properties of reinforcement material}

The geocell was created, using a polymeric sheet after testing of tensile properties according to ASTM D 882 [31]. The resistance properties and the stress-strain curve of the sheet are as shown in Table 2 and Fig. 3, respectively.

\subsubsection{Laboratory test procedure}

Direct shear tests were carried out on a large scale and square-shape box with dimensions of $30 \mathrm{~cm}$. The tests were first conducted on the unreinforced soil to determine the cohesion value and the internal friction angle of the soil, with different overburdens of 49,98 and $196 \mathrm{kPa}$, respectively. In order to mould soil in the shear box, it was prepared at the optimum moisture content and compacted in three layers. For the first and last layers, a square-shape tamper, with a dimension of $75 \mathrm{~mm}$ and weight of $2500 \mathrm{gr}$, was applied. A bullet-nosed metal rod measuring $16 \mathrm{~mm}$ in diameter with a $600 \mathrm{~mm}$ long, was used to tamp soil inside the whole geocell pockets, placed in the second layer. Then a test, applying the maximum overburden of the previous tests, was carried out on the geocell-reinforced soil. Therefore, the results would be a yardstick for software calibration.

The maximum particle size of soil was considered as the minimum size of the geocell opening. The height of the geocell was also taken the same account of its opening size. Owing to the mentioned scales adopted herein, entire soil particles could be disposed into the interior of the geocell pockets and, consequently, effectively compacted. The geocell was installed inside the shear box, such that the predetermined failure plane cross through the middle of the geocell height (see Fig. 4).

Table 2 Polymer sheet features

\begin{tabular}{llllll}
\hline $\begin{array}{l}\text { Thickness } \\
(\mathrm{mm})\end{array}$ & $\begin{array}{l}\text { Weight } \\
\text { per unit } \\
\text { area }(\mathrm{g} / \\
\left.\mathrm{m}^{2}\right)\end{array}$ & $\begin{array}{l}\text { Yield } \\
\text { strength } \\
(\mathrm{MPa})\end{array}$ & $\begin{array}{l}\text { Ultimate } \\
\text { strength } \\
(\mathrm{MPa})\end{array}$ & $\begin{array}{l}\text { Strain } \\
\text { at yield } \\
\text { point }(\%)\end{array}$ & $\begin{array}{l}\text { Elastic } \\
\text { modulus } \\
(\mathrm{MPa})\end{array}$ \\
\hline 0.5 & 632.2 & 3.24 & 6.33 & 10.9 & 20.54 \\
\hline
\end{tabular}

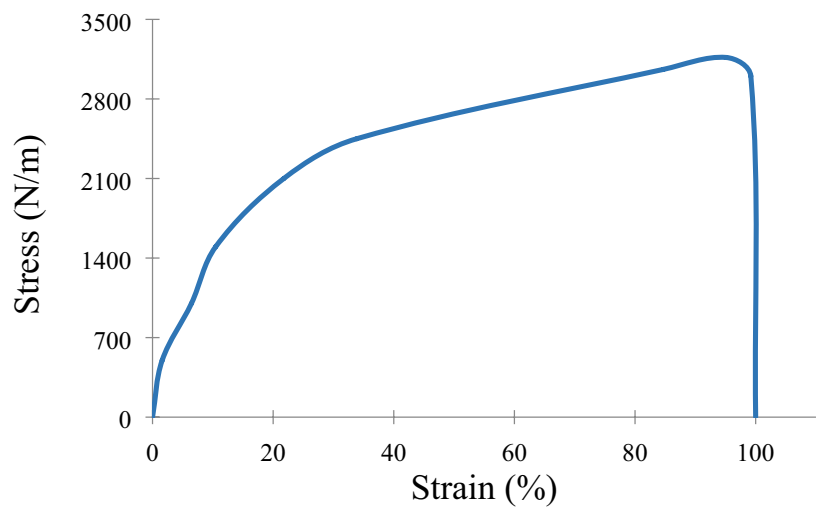

Fig. 3 Polymer sheet stress-strain curve

\subsection{Finite element modeling}

To evaluate the trend of shear stress-horizontal displacement curves, ABAQUS software was used to simulate tests in a three-dimensional state.

\subsubsection{Constitutive model of the soil and the failure criterion}

Numerical methods in geotechnics include the following principles: boundary conditions, compatibility, equilibrium and constitutive equations. Constitutive laws define the relationship between stress and strain, containing the failure criterion. These equations that describe the behavior of materials can be interpreted as constitutive models

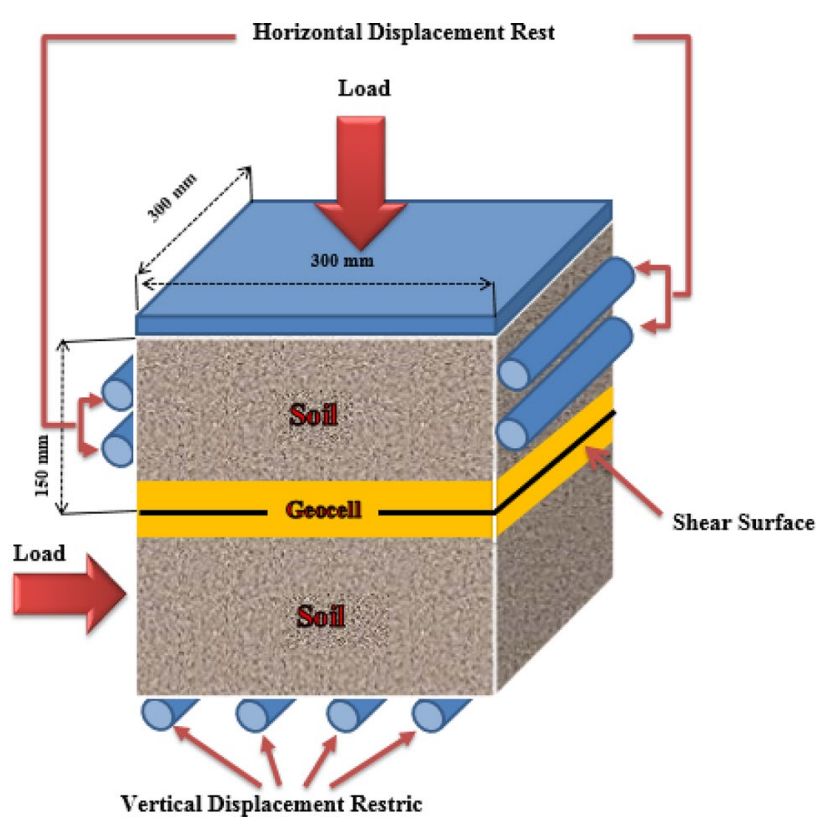

Fig. 4 A schematic diagram of the direct shear test set-up 
of materials. The model of "Mohr-Coulomb" was used to evaluate the soil function. The model involves strength parameters including cohesion $(C)$, angle of internal friction $(\varphi)$ and dilatancy angle $(\psi)$ and parameters of deformability including Young's modulus $(E)$ and Poisson ratio $(v)$ [32]. This elasto-plastic model is one of the most widely used models in geotechnical numerical analysis. In Mohr's model, the Mohr-Coulomb failure criterion is used as the yield surface, and the flow rule in shear mode is assumed to be independent.

In 1773 , Coulomb published an essay presenting a failure criterion as follows:

$\tau=\mathrm{c}+\sigma \tan \varphi$

where $(\tau)$ and $(\sigma)$, respectively, represent shear stress and normal stress on the physical surface where material failure occurs. Later, Mohr combined this criterion with the principal stresses, and the Mohr-Coulomb model was formed.

\subsubsection{Parametric calculations of reinforced soil properties}

A number of investigators [21, 22] remarked that geocell confinement in soil induces apparent cohesion, whereas the reinforcement depth is replaced by an equivalent layer, with homogenous properties [33]. The induced cohesion in the soil is related to the increase in the confining pressure on the soil due to the geocell reinforcement, which is calculated through the following equation:

$C r=\frac{\Delta \sigma_{3}}{2} \sqrt{K_{p}}$

where $\left(\Delta \sigma_{3}\right)$ is the increase in the confining pressure due to the geocell, and $(K p)$ is the coefficient of passive earth pressure [34]. On the other hand, Henkel and Gilbert [35] proposed the membrane correction theory to obtain the increment of the confinement due to geocell:

$\Delta \sigma_{3}=\frac{2 M}{d_{o}}\left[\frac{1-\sqrt{1-\varepsilon_{a}}}{1-\varepsilon_{a}}\right]$

where $\left(\varepsilon_{a}\right)$ is the axial strain of the geocell materials, $\left(d_{o}\right)$ is the initial diameter of individual cell pocket, and $(M)$ is the modulus of the geocell material corresponding to the axial strain of $\left(\varepsilon_{a}\right)$ [10].

In order to determine the total cohesion of reinforced soil, the apparent cohesion due to the geocell function should be added to the unreinforced soil cohesion as follows:

$C_{g}=C_{r}+C$
In this analysis, the reinforced layer through geocell behaves like an equivalent soil layer with greater cohesive strength than unreinforced soil. Based on the triaxial compression test on geocell-encased sand, the following empirical equation was proposed to express Young's modulus of geocell-reinforced sand $(E g)$ :

$E_{g}=4\left(\sigma_{3}\right)^{0.7}\left(K_{u}+200 M^{0.16}\right)$

where $\left(K_{u}\right)$ is the dimensionless modulus parameter of the unreinforced sand that corresponds to the modulus number in the hyperbolic model [36].

Based on the proposed equations, using the parameters of soil and geocell material presented, the modulus of elasticity was obtained by $127.27 \mathrm{MPa}$, and the values of overall reinforcement cohesion were achieved by $28.35,22.35$ and $19.02 \mathrm{kPa}$ for geocells having the diameter of 25, 35 and $45 \mathrm{~mm}$, respectively. For example, a geocell with a square opening with $25 \mathrm{~mm}$ dimensions has an equivalent diameter of $28.2 \mathrm{~mm}$ (corresponding to a circle having the same area). At a strain of $10 \%$, considering the stiffness of $11.72 \mathrm{kN} / \mathrm{m}$, the increase in the confining pressure (3) due to the geocell is $21.9 \mathrm{kPa}$. Consequently, the induced cohesin (2) would be $20.99 \mathrm{kPa}$. Eventually, the overall cohesion (4) of the geocell reinforced soil is obtained by $28.35 \mathrm{kPa}$.

\subsubsection{Details of the model and boundary conditions}

The three-dimensional analysis of ABAQUS software was done using two steps of computation, as shown in the figure below (Fig. 4). An overburden load of $196 \mathrm{kPa}$, the same value used in model verification, was applied to the top of the shear box. Then the shear load was applied horizontally to the lower half box by controlling the value of displacement. Aiming to have an integrated soil mass, two parts of soil with Tie interaction were connected. Thus, there was no relative deformation between these two levels through interaction. There was also normal and tangential interaction between the surface of soil and box. For the upper box, displacement was restricted by the boundary conditions that did not allow the upper box to move in the horizontal direction. Related to the lower box, the movement restriction was applied in the vertical direction, and therefore its motion was just horizontally possible. Additionally, in the present numerical modeling with ABAQUS, 386 C3D8R elements and 172 nodes for the box, and 1800 C3D8R elements and 2560 nodes for the soil, were used. 
Fig. 5 Shear stress and horizontal displacement contours for the soil body under direct shear test under $196 \mathrm{kPa}$ overburden

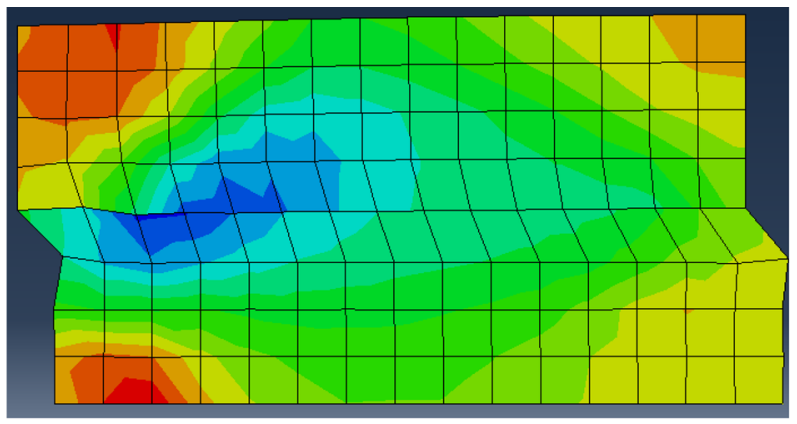

a Shear stress contour of unreinforced soil

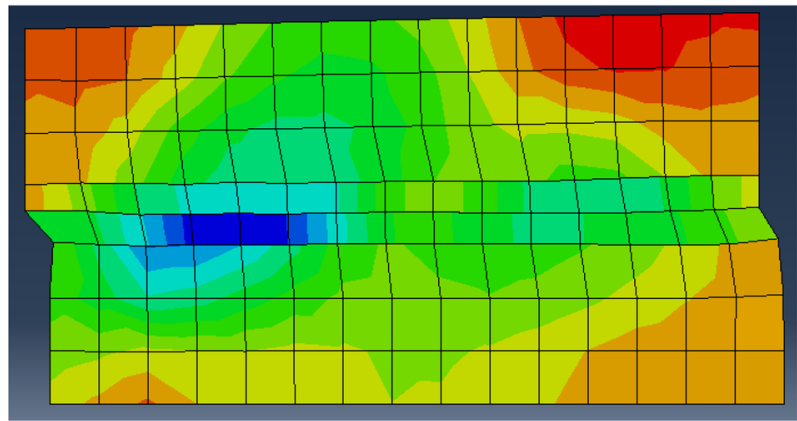

b Shear stress contour of reinforced soil

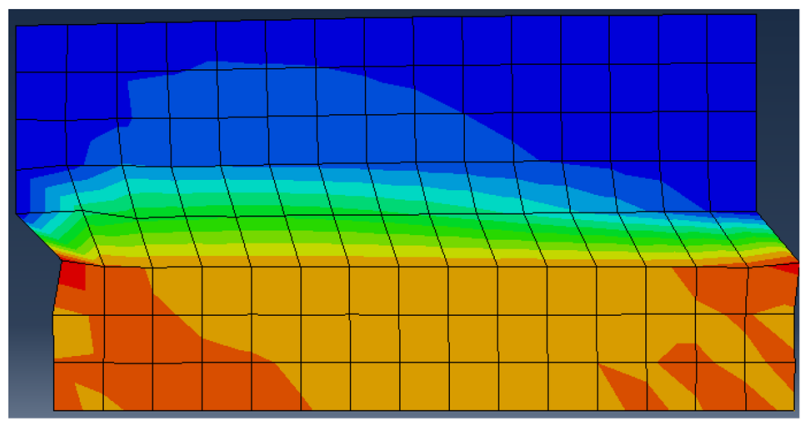

c Horizontal displacement contour of unreinforced soil

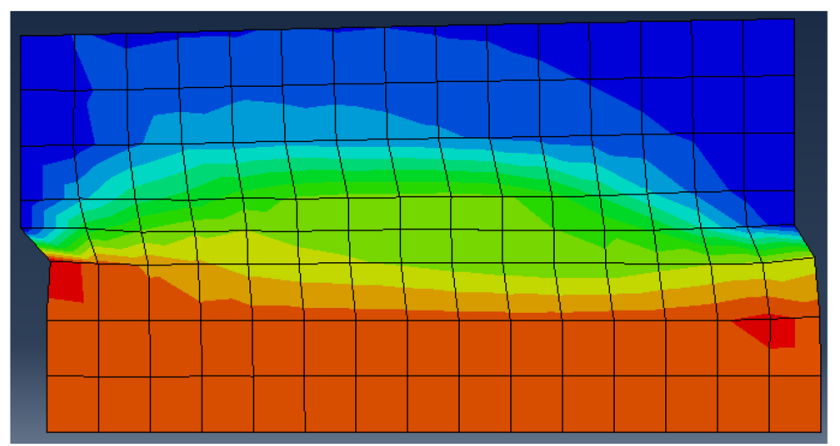

d Horizontal displacement contour of reinforced soil
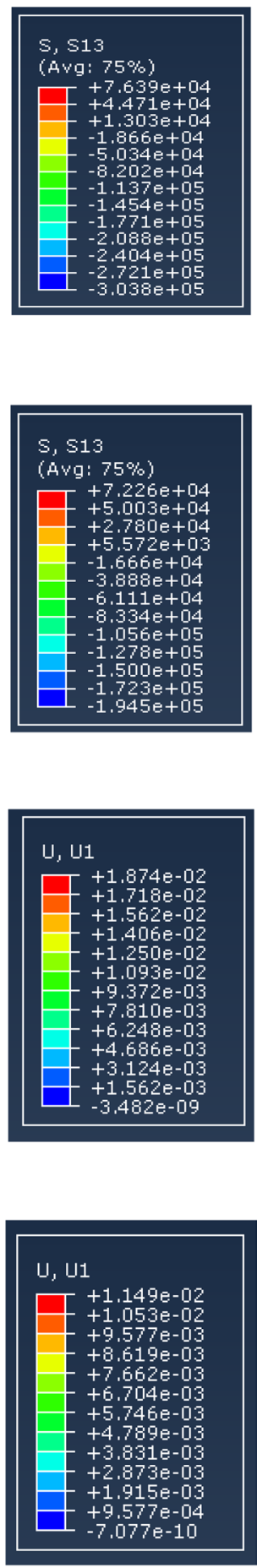

\subsubsection{Model verification}

Before the numerical simulation, using laboratory results, the model was validated, and then examined the effects of different variables on the shear strength of the soil. For model verification, the shear stress-horizontal displacement curve, obtained from the large-scale laboratory direct shear test on unreinforced soil, was plotted against the software simulation chart. Then, the experimental results of geocell-reinforced soil, with a pocket opening size of $25 \mathrm{~mm}$ and a height of $25 \mathrm{~mm}$, were compared with the simulated model under the same condition.

\section{SN Applied Sciences}


Contours of shear stress and horizontal displacement of soil body, under an overburden of $196 \mathrm{kPa}$, is presented in Fig. 5. Comparing the experiment and simulation results (see Fig. 6) reveals that the generated model can perform the simulation acceptably. The model simulated can present the maximum shear strength with good accuracy. Besides, the strains obtained are relatively nearby the reality.

\subsubsection{Numerical simulation of model}

The direct shear test was simulated by three quadrangular geocell with pocket opening diameters of 25, 35 and $45 \mathrm{~mm}$, to investigate the effect of the opening size of geocell on the shear strength parameters, where all reinforcements were installed at the middle height of the shear box. In order to determine the efficacy of geocell layout, a geocell, with a diameter and height of $25 \mathrm{~mm}$, was used in the three tests carried out in this study. In the first test, the failure plane completely passes through the middle height of the geocell $(S=12.5 \mathrm{~mm})$, where " $S$ " refers to a part of geocell height, which remained in the upper box. In the tow next step, the geocell brings down by a quarterheight. So, the " $S$ " value is 6.25 and 0 in millimeter. Additionally, it was attempted to evaluate the effect of aspect ratio versus interfacial shear strength, using a different method. For this purpose, instead of keeping the height constant and changing the diameter performed by Manju [18], the pocket diameter was kept constant at $25 \mathrm{~mm}$, and the geocell height was varied between 15, 20, 25, 30 and
$35 \mathrm{~mm}$. And, finally, two series of tests were carried out using geocell with the heights of 15 and $25 \mathrm{~mm}$, to determine the effect of reinforcement on the shear strength of the soil between two layers of geocell. The pocket diameter was kept constant at $25 \mathrm{~mm}$, and the test simulated, where geocells installed at different distances from each other. Firstly, both geocells were tangent to the predetermined failure plane, then, they got away from each other in two steps, each time as the same of geocell height.

\section{Results and discussion}

\subsection{Effect of geocell-pocket opening size}

A significant increase in the shear strength of the soil occurred as a result of the reinforcement. Based on the results shown in Fig. 7, this desirable effect increased following the decrease in the diameter of geocell. The smallest diameter intended for the geocell is $25 \mathrm{~mm}$, which is the least possible size for this purpose considering the maximum size of the soil particles.

As shown in the mentioned figure, a decrease and subsequent an increase in stress, after horizontal displacement of about $7 \mathrm{~mm}$, are observed. The decrease in stress probably results from the loss of total cohesion $\left(C_{g}\right)$ in the case of the geocell-reinforced soil model. On the other hand, stress increases again due to the role of frictional resistance of sand particles, which controls the stress level after initial displacement. Based on the
Fig. 6 Comparison between experimental and numerical results

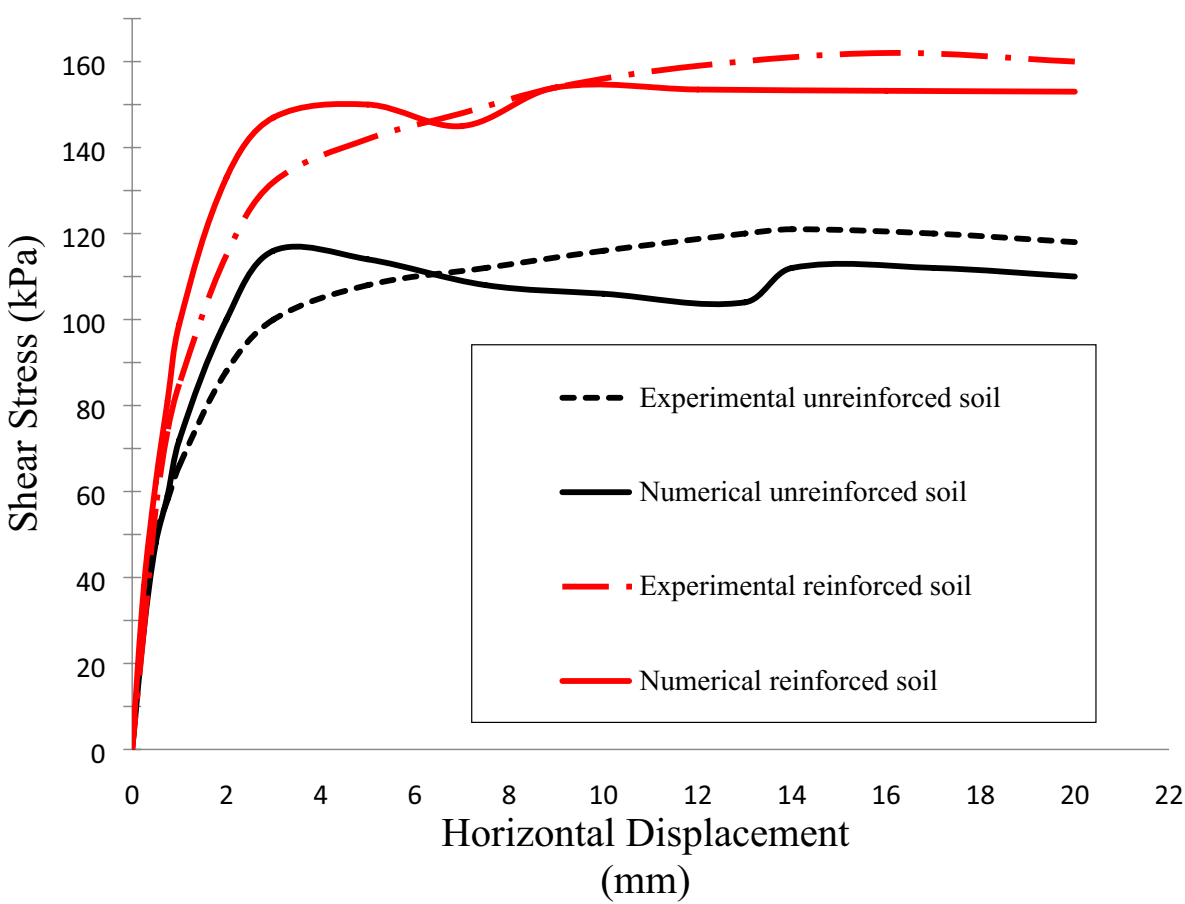

SN Applied Sciences 
Fig. 7 Effect of pocket opening size on shear strength of reinforced soil

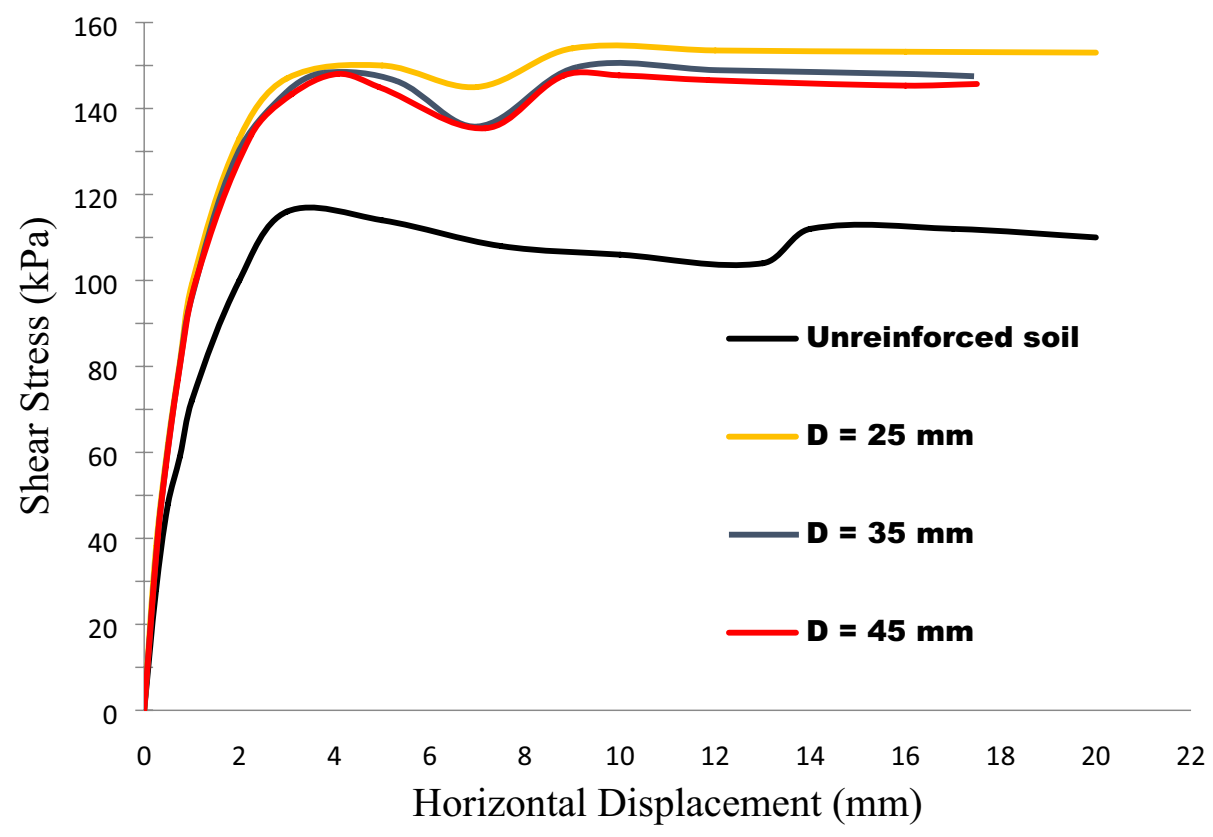

assumptions made in this study, the existence of geocell is attributed to the augmentation of cohesion. In this simulation, the soil thickness containing geocell has been replaced, with materials that not only have the characteristics of the base granular soil but also have significant cohesion. This situation can be equated with re-increasing the stress caused by the passive resistance activation, due to displacement increment, in the experimental tests [19].

In Fig. 8a, the effect of pocket opening size on the increased shear strength percentage is shown. According to the results, with an increase of $80 \%$ in the diameter, $5 \%$ of its shear strength reduces. Although this statement needs to be confirmed in large-scale practical work, the geocell design should nevertheless take into account the economic issues and operational problems of producing and using geocells with smaller pocket diameters.
The ratio of the height of the geocell to its diameter is referred to as aspect ratio. Pocket diameter and aspect ratio of geocells influence the interfacial cohesion significantly. The increment of the confined sand area resulting from a smaller pocket size or higher aspect ratio leads to an increase in interfacial cohesion [18]. Based on the numerical results of this laboratory scale, Fig. $8 \mathrm{~b}$ shows a correlation between the aspect ratio of geocell and shear strength increment.

\subsection{Efficacy of the geocell layout}

The results, as presented in Fig. $9 a$, show that the shear strength values obtained by direct shear test of the reinforced section, when failure plane crosses reinforcing element, as can be seen in the schematic placed in Fig. 9a are significantly greater than those resulting
Fig. 8 Effect geocell-pocket opening size on the increased shear strength percentage

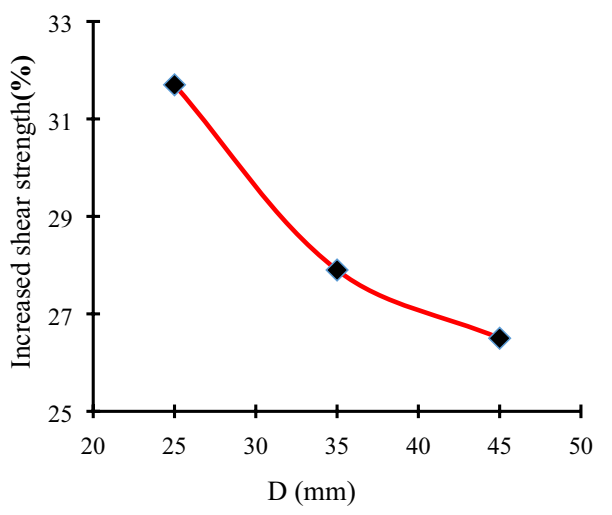

a Effect of pocket diameter

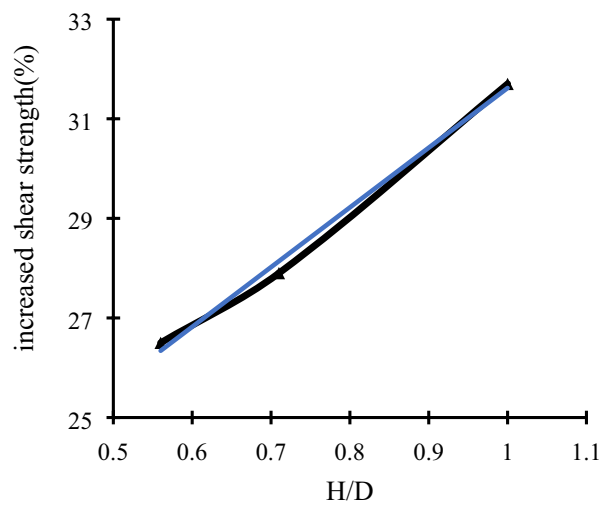

b Effect of aspect ratio (H/D) 
Fig. 9 Effect of geocell layout on the shear strength

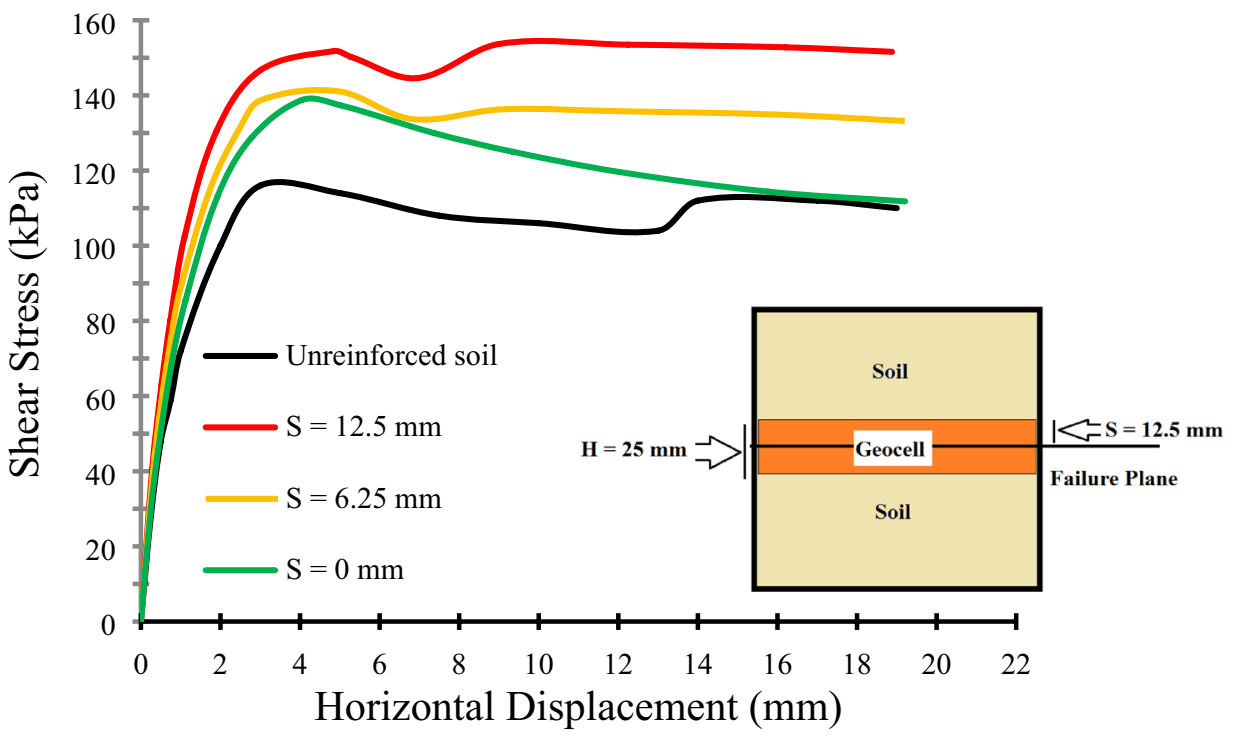

a Effect of geocell placement on the shear strength of reinforced soil

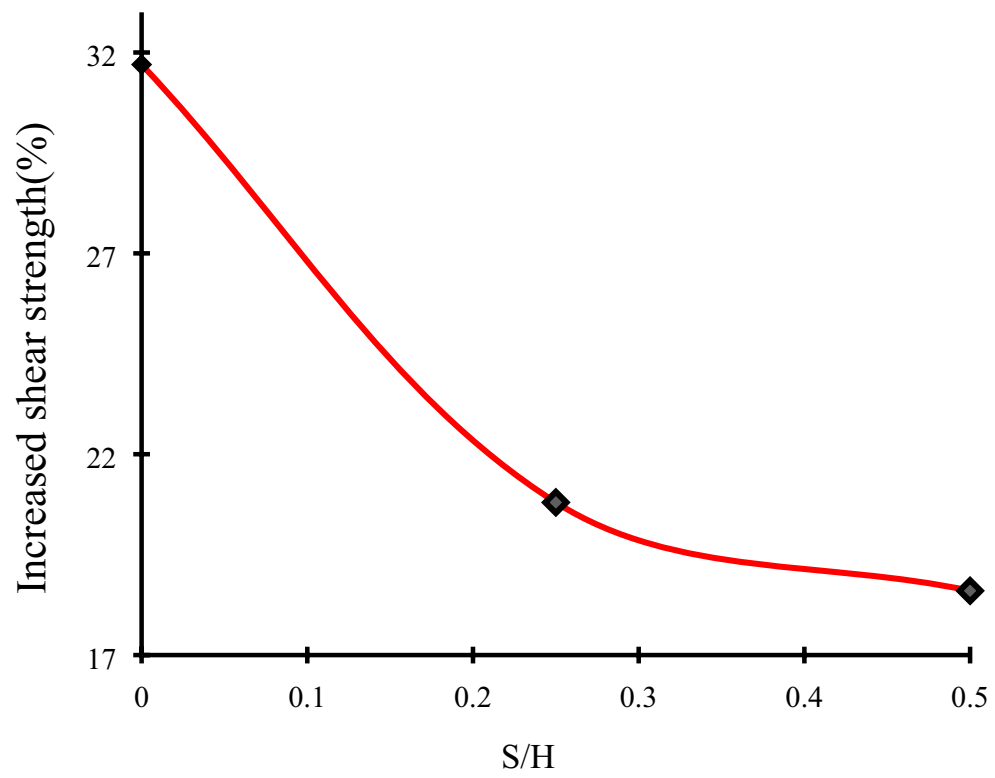

b Dimensionless effect of geocell placement on the increased shear strength percentage from the interaction between the reinforcement and soil $(S=0 \mathrm{~mm})$. On the other hand, in this case, the shear stress horizontal displacement curve indicates that after reinforced soil failure, its shear strength tends toward that of the unreinforced soil. However, in other cases, a decrease in shear strength is observed due to incipient failure. As the displacement increases, the pull-out resistance applies in the opposite direction of shear, which moves/turns the model into a passive state. Therefore, a further increase in shear strength can be seen (up to the ultimate pull-out resistance of the reinforced soil or the rupture resistant of the geocell). Depending on the depth of geocell involvement and the geosynthetic tensile strength used in geocell fabrication, this increase in shear strength may be more or less.

In Fig. 9b, the effect of dimensionless changes of geocell placement related to the failure plane is shown using the percentage of maximum shear strength increment compared with that of unreinforced soil. The closer the geocell middle height is to the failure plane, the more effective it is for increasing shear strength. Distancing the geocell from the failure plane reduces the pull-out resistance and, therefore, the shear strength. 


\subsection{Geocell height effect}

The results of modeling clarified, unlike previous studies, not only the ultimate strength of all geocells, with different heights, were the same, but also the reinforced samples with an aspect ratio of 0.8 and more $(H \geq 20)$ had the same stress-strain behavior (Fig. 10a). This discrepancy in the statements can be explained by the fact that in previous studies, although the interfacial shear strength increased with increasing aspect ratio, the reason what improved soil resistance properties was the increase in the number of pockets per unit area, not the aspect ratio. The smaller diameter of the geocell consequents a more number of pockets, and also the larger confining area of the geocell with the interface [18]. Thus, it can more improve the shear properties. But, this does not happen with the height
Fig. 10 Geocell height effect on the interfacial shear strength

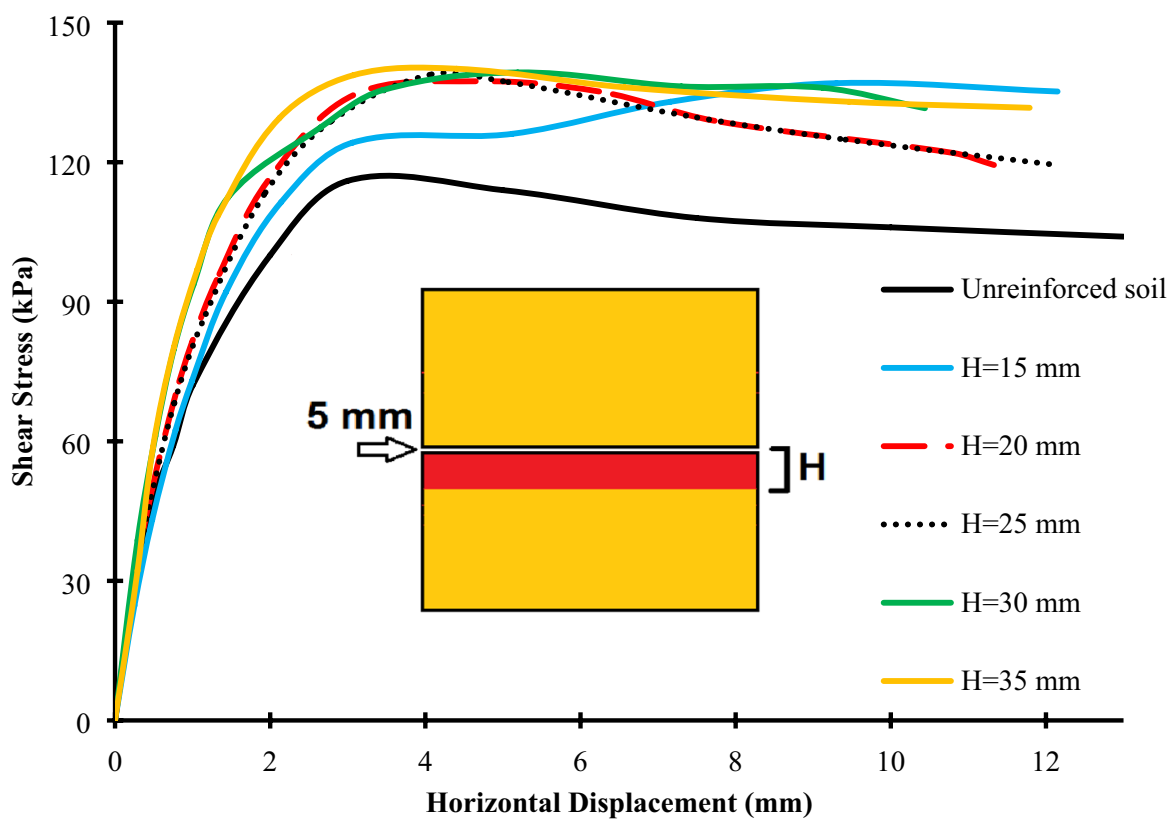

a Effect of geocell height on the shear strength of reinforced soil

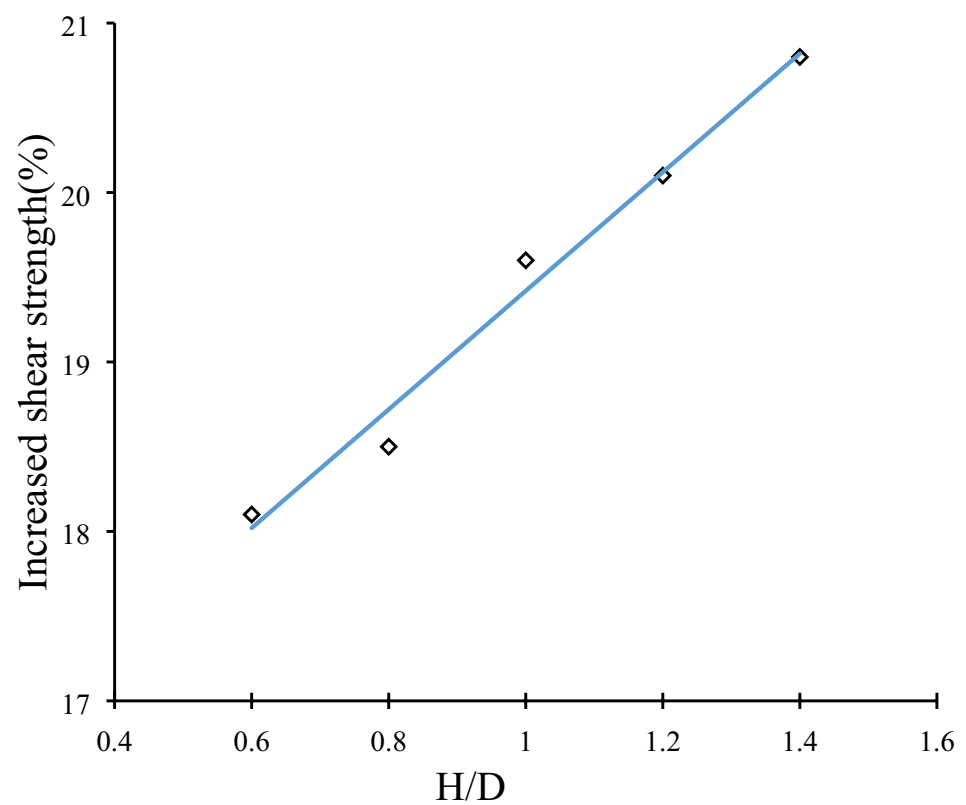

b Effect of aspect ratio (H/D) on the increased interaction in shear strength percentage 
Fig. 11 Shear strength increment between two layers of geocell

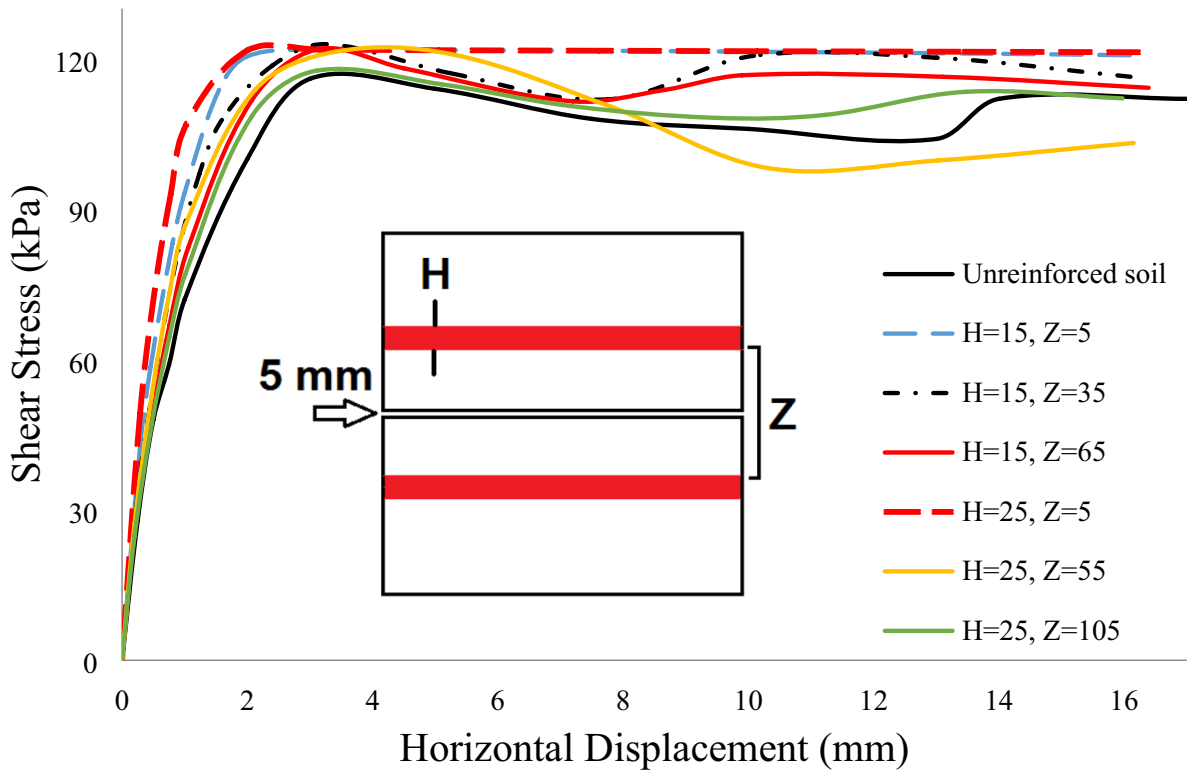

increment, and therefore the changes made on the aspect ratio cannot mobilize more interaction and have a significant effect.

Figure $10 \mathrm{~b}$ shows the effect of geocell aspect ratio on the shear strength between soil and geocell edge. Based on the figure, data points with a high positive correlation are aligned, which is similar to Fig. 8b. With a difference that, in the former simulation, it was assumed the predetermined failure plane passes through the geocell layer. While, in the latter case, the failure occurs at the interface between the geocell and soil. Besides, if an increase is caused, in the aspect ratio, by a decrease in the diameter of the geocell pockets (Fig. 8b), the rate of increment in shear resistance is more, compared to the cases where increases in the aspect ratio are a result of adding to the geocell height (Fig. 10b). Due to the above reasons, the rate of shear resistance increment, in Fig. $8 \mathrm{~b}$ is 3.43 times more than that presented in Fig. 10b. If the aspect ratio is assumed to be zero $(\mathrm{H}=0)$, the geocell converts into a geogrid, which causes an increase in the shear strength of the reinforced soil. The values of width of origin, in the two mentioned figures, indicate the effect of hypothetical geogrids on the interface shear strength. As is observable, the widths of the origins have a nonconformity, too. It is due to a shift in the location of hypothetical geogrids. As shown in Fig. 10a, a distance of $5 \mathrm{~mm}$, between the two halves of the shear box, is considered. The middle of the geocell height, in the previous model simulation (Fig. 8b), was located at the center of spacing, exactly. While, in the simulation case for Fig. 10b, the middle height is level with the edge of the lower half of the box. Therefore, the effect of geocell, as well as the hypothetical geogrid, for the simulation performed in Fig. $8 \mathrm{~b}$, is more prominent.

\subsection{Shear strength increment between two layers of geocell}

When the two layers of geocell are tangent to the top and bottom of the failure plane, there is only one thin layer of $5 \mathrm{~mm}$ thickness between them; consequently, the reinforcements increase the maximum shear strength approximately by $5 \%$ (see Fig. 11). In this condition, the shear strength is stabilized after reaching about $121 \mathrm{MPa}$, and there is no increase or decrease during the shearing process. These models have perfect plastic behavior after failure. This may be due to lack of distribution and no variations in shear stress, concerning the fact that the geocell layers are stiffer than the soil between them. Then, the geocell layers took some distance from the failure plane (In two stages and each time equal to the height of the geocell), and the direct shear test was simulated on these sets at each stage. The results show a decrement in shear strength after failing in the cases of unreinforced soil and reinforced soil by separated geocell layers. Overall, however, shear strength increased by about $5 \%$ due to reinforcement.

\section{Conclusion}

The results show that in the reinforced soil tested at $196 \mathrm{kPa}$ overhead pressure, shear strength increase by more than $30 \%$. The amount of this increase depends on the opening size of the geocell and the position of geocell placement. The various effects of the reinforcement on the shear strength are summarized as follows: 
1. Geocell with a smaller pocket opening size increases the shear strength of the soil more significantly. The most increment is up to $31 \%$ for the geocell with the smallest pocket opening size of $25 \mathrm{~mm}$ (equal to the maximum size of soil particles).

2. By the increment, up to $80 \%$, in the pocket opening diameter, the value of shear strength decreases by around $5 \%$.

3. When the failure plane passes exactly through the middle of the geocell height, the shear strength increment is $11 \%$ more compared to the one in the state whereby the edge of geocell is tangential with the failure plane.

4. When the geocell moves away from the failure plane, the shear strength resulting from the direct shear test is highly similar in trend to the results of the unreinforced soil. It was found that the increment of shear strength is $5 \%$ at maximum shear strength.

5. If the two layers of the geocell place very close to each other during displacement, the shear strength between them completely stabilizes after failure and shows no increase or decrease.

6. The increase in aspect ratio, arising from the height increment, is not effective in the interfacial shear strength improvement.

Acknowledgements Authors would like to thank “Dr. Salahudeen Anigilaje Bunyamin, University of Jos, Jos, Nigeria, and Eng. Bahman Arabi, Technical \& Soil Mechanics Laboratory of Roads and Urban Development Ministry, Semnan, Iran" for their supports.

\section{Compliance with ethical standards}

Conflict of interest The authors declare that they have no conflict of interest.

\section{References}

1. Hejazi SM, Sheikhzadeh M, Abtahi SM, Zadhoush A (2012) A simple review of soil reinforcement by using natural and synthetic fibers. Constr Build Mater 30:100-116. https://doi.org/10.1016/j. conbuildmat.2011.11.045

2. Jalili M, Kabiri M (2019) The effect of reinforced soil type on the value of bearing ratio. In: 16th Asian Regional Conference on Soil Mechanics and Geotechnical Engineering (16ARC). Taipei, Taiwan. https://www.researchgate.net/publication/336717145

3. Nicholson PG (2014) Soil improvement and ground modification methods. Butterworth-Heinemann. https://doi.org/10.1016/ B978-0-12-408076-8.00014-5

4. Xu C, Liang C, Shen P, Chai F (2020) Experimental and numerical studies on the reinforcing mechanisms of geosynthetic-reinforced granular soil under a plane strain condition. Soils Found. https://doi.org/10.1016/j.sandf.2020.03.003

5. Palmeira EM, Tatsuoka F, Bathurst RJ, Stevenson PE, Zornberg JG (2008) Advances in geosynthetics materials and applications for soil reinforcement and environmental protection works. Electron J Geotech Eng 13:1-38

6. Ahmad H, Mahboubi A, Noorzad A (2020) Scale effect study on the modulus of subgrade reaction of geogrid-reinforced soil. SN Appl Sci 2(3):1-22. https://doi.org/10.1007/s42452-020-2150-4

7. Alabbasi Y, Hussein M (2019) Large-scale triaxial and box testing on railroad ballast: a review. SN Appl Sci 1:1592. https://doi. org/10.1007/s42452-019-1459-3

8. Ehrlich M, Becker L (2010) Reinforced soil walls and slopes: design and construction. Oficina de Textos

9. Zhang L, Zhao M, Shi C, Zhao H (2010) Bearing capacity of geocell reinforcement in embankment engineering. Geotext Geomembr 28(5):475-482. https://doi.org/10.1016/j.geote xmem.2009.12.011

10. Yang X, Han J, Parsons RL, Leshchinsky D (2010) Threedimensional numerical modeling of single geocell-reinforced sand. Front Archit Civil Eng China 4(2):233-240. https://doi. org/10.1007/s11709-010-0020-7

11. Leshchinsky B, Ling HI (2013) Numerical modeling of behaviour of railway ballasted structure with geocell confinement. Geotext Geomembr 36:33-43. https://doi.org/10.1016/j.geote xmem.2012.10.006

12. BSI-BS 8006-1 (2010) Code of practice for strengthened/reinforced soils and other fills. British Standards Institution

13. Bathurst RJ, Karpurapu R (1993) Large-scale triaxial compression testing of geocell-reinforced granular soils. Geotech Test J 16(3):296-303. https://doi.org/10.1520/GTJ10050J

14. Rajagopal K, Krishnaswamy N, Latha GM (1999) Behaviour of sand confined with single and multiple geocells. Geotext Geomembr 17(3):171-184. https://doi.org/10.1016/S0266 -1144(98)00034-X

15. Mehdipour I, Ghazavi M, Moayed RZ (2013) Numerical study on stability analysis of geocell reinforced slopes by considering the bending effect. Geotext Geomembr 37:23-34. https://doi. org/10.1016/j.geotexmem.2013.01.001

16. Saride S, Gowrisetti S, Sitharam TG, Puppala AJ (2009) Numerical simulation of geocell-reinforced sand and clay. Proc Inst Civil Eng Ground Improv 162(4):185-198. https://doi.org/10.1680/ grim.2009.162.4.185

17. Latha GM, Rajagopal K, Krishnaswamy N (2006) Experimental and theoretical investigations on geocell-supported embankments. Int J Geomech 6(1):30-35. https://doi.org/10.1061/ (ASCE)1532-3641(2006)6:1(30)

18. Manju G, Latha GM, Rajeshkannan D (2014) Effect of pocket size on the shear properties of different sand-geocell interfaces. Paper presented at the 10ICG, Berlin, Germany. https://www. researchgate.net/publication/270583865

19. Vallejo LE, Mawby R (2000) Porosity influence on the shear strength of granular material-clay mixtures. Eng Geol 58(2):125-136

20. Chung W, Cascante G (2007) Experimental and numerical study of soil-reinforcement effects on the low-strain stiffness and bearing capacity of shallow foundations. Geotech Geol Eng 25(3):265-281. https://doi.org/10.1007/s10706-006-9109-0

21. Cicek E, Guler E, Yetimoglu T (2018) Stress distribution below a continuous footing on geotextile-reinforced soil. Int J Geomech 18(3):06018005. https://doi.org/10.1061/(ASCE)GM.19435622.0001095

22. Magade SB, Ingle RK (2019) Numerical method for analysis and design of isolated square footing under concentric loading. Int J Adv Struct Eng 11(1):9-20. https://doi.org/10.1007/s4009 1-018-0211-3

23. Leshchinsky B, Ling $H$ (2012) Effects of geocell confinement on strength and deformation behaviour of gravel. J Geotech Geoenviron Eng 139(2):340-352. https://doi.org/10.1061/(ASCE) GT.1943-5606.0000757 
24. Wang Y-M, Chen Y-K, Liu W (2008) Large-scale direct shear testing of geocell reinforced soil. J Central South Univ Technol 15(6):895. https://doi.org/10.1007/s11771-008-0163-z

25. AASHTO M 147 (2012). Standard Specification for Materials for Aggregate and Soil-Aggregate Subbase, Base, and Surface Courses. American Association of State Highway and Transportation Officials

26. ASTM D854-14, Standard Test Methods for Specific Gravity of Soil Solids by Water Pycnometer. ASTM International, West Conshohocken, PA, 2015. www.astm.org

27. ASTM C127-15, Standard Test Method for Relative Density (Specific Gravity) and Absorption of Coarse Aggregate, ASTM International, West Conshohocken, PA, 2015. www.astm.org

28. ASTM C128-15, Standard Test Method for Relative Density (Specific Gravity) and Absorption of Fine Aggregate. ASTM International, West Conshohocken, PA, 2015. www.astm.org

29. ASTM D1557-12e1, Standard Test Methods for Laboratory Compaction Characteristics of Soil Using Modified Effort $(56,000$ $\mathrm{ft}-\mathrm{lbf} / \mathrm{ft} 3(2,700 \mathrm{kN}-\mathrm{m} / \mathrm{m} 3))$, ASTM International, West Conshohocken, PA, 2012. www.astm.org

30. BSI-BS 1377-7 (1990), Methods of test for Soils for civil engineering purposes - Part 7: Shear strength tests (total stress)

31. ASTM D882-18, Standard Test Method for Tensile Properties of Thin Plastic Sheeting, ASTM International, West Conshohocken, PA, 2018, www.astm.org
32. Medzvieckas J, Dirgèlienè N, Skuodis Š (2017) Stress-strain states differences in specimens during triaxial compression and direct shear tests. Procedia Eng 172:739-745. https://doi. org/10.1016/j.proeng.2017.02.094

33. Zidan AF, Mohamed M (2019) Numerical analysis of bearing capacity of multiple strip footing on unreinforced and reinforced sand beds. SN Appl Sci 1:1499. https://doi.org/10.1007/ s42452-019-1520-2

34. Latha GM, Somwanshi A (2009) Effect of reinforcement form on the bearing capacity of square footings on sand. Geotext Geomembr 27(6):409-422. https://doi.org/10.1016/j.geote xmem.2009.03.005

35. Henkel D, Gilbert G (1952) The effect measured of the rubber membrane on the triaxial compression strength of clay samples. Geotechnique 3(1):20-29. https://doi.org/10.1680/ geot.1952.3.1.20

36. Latha GM, Rajagopal K (2007) Parametric finite element analyses of geocell-supported embankments. Can Geotech J 44(8):917927. https://doi.org/10.1139/T07-039

Publisher's Note Springer Nature remains neutral with regard to jurisdictional claims in published maps and institutional affiliations. 